\title{
The Effect of E-Content Designed by Absorb-Type Activities on the Learning and Retention of Students
}

\author{
Ehsan Toofaninejad, ${ }^{1, *}$ and Azad Alahkarami ${ }^{1}$ \\ ${ }^{1}$ Educational Technology, School of Psychology and Education, Allameh Tabataba'i University, Tehran, Iran \\ "Corresponding author: Ehsan Toofaninejad, Educational Technology, School of Psychology and Education, Allameh Tabataba'i University, Tehran, Iran. Tel: +98-9123154067, \\ E-mail: toofanien@yahoo.com
}

Received 2017 February 26; Accepted 2017 March 15.

\begin{abstract}
Background: Absorb-type activities are informative and inspiring. Such activities stimulate learners to access the updated information they need. They have been known as an effective and necessary part to design e-learning content. This study aimed at comparing the effect of e-content designed by absorb-type activities approach with conventional e-content on the learning and retention of students.

Methods: This was a quasi-experimental study with pre- and posttest, and control group. The study population included thirdgrade students at a high school in Tehran. Using convenience sampling technique, 52 students were selected and randomly assigned into 2 experimental and control groups. The experimental group was trained by e-content, designed by the absorb-type activities approach, while the control group was trained by e-content designed by conventional methods. The measurement instrument was expert-made pre-and posttests in physics. The reliability of the pretest and posttest using Cronbach's alpha coefficient was 0.82 and 0.89 , respectively. Experts and physics teachers also confirmed the face and content validity. For data analysis, descriptive (mean and standard deviation) and inferential statistics (analysis of covariance), and SPSS version 16 software were used.

Results: The study results revealed that the mean difference of learning (17.15 \pm 1.15$)$ and retention scores (14.84 \pm 2.41$)$ in the experimental group was significantly different from learning $(14.61 \pm 1.89)$ and retention scores $(12.92 \pm 2.71)$ in the control group (learning: $\mathrm{P}=0.001$; retention: $\mathrm{P}=0.008$ ).

Conclusions: According to the results of the study, designing e-learning content with absorb-type activities approach had a positive effect on increasing learning and retention of students compared to conventional e-content and can be used to enrich e-content.
\end{abstract}

Keywords: E-Learning, Absorb-Type Activities, E-Content, Educational Technology, Education, Student

\section{Background}

Along with the advent of information technology, the process of global development has been rapidly expanding, with a focus on information and knowledge elements. For more than a decade, this phenomenon has been established in the field of education and challenged educational systems and environments. Given the speed, extension, and depth of development caused by information technology, recognizing the characteristics and informative and intelligent management of this phenomenon can be one of the most important strategies of those involved in education in the country and can provide an opportunity to rebuild the education system and change the teachinglearning process (1).

One of the most important factors affecting e-learning is the type of educational content and interaction with students (2). The production of e-content is the issue introduced by the expansion of the internet in the educational environment since the 90s; and in the recent years, private companies and many universities have tried to prod- uct e-content (3). E-learning environment provides various learning activities to cover a variety of learning styles. To achieve learning objectives, Horton suggested 3 types of learning activities to design e-content including absorb-, do- and connect- type activities. He presented these 3 approaches with an emphasis on the fact that many of the activities that can be done in face- to-face classes can be done in an e-classroom (4).

In absorb-type activities, learners read, watch, and listen; in do-type activities, learners do everything such as exercise, research, and exploration by the gained knowledge; and in connect-type activities, learners are directed towards the connection of new learning with real life, job, and previous knowledge. The reason for selecting absorb-type activities from the 3 main activities to design e-content is that in most e-learning and in-person courses a part of education content is provided by a teacher and teacher-centered activities are used to provide educational content, which compared to other activities is increased by an increase in the number of students in the class. However, studies show that most students' dissatisfaction with 
e-courses is due to the lack of capability of the instructor at the presentation, long-term presentation, and inappropriately designed content (5). Courses' teachers also consider the unsuitable design of educational content as one of the causes of failure in increasing students' satisfaction and learning (6). The solutions reported to improve this problem include teachers' short-term presentation, designing according to the principles of presentation, rich content, and cognitive management of learners and teachers by different methods (7). Absorb-type activities have been known as the first step to design e-content (4) and have attracted the focus of instructional designers to the piece of content provided by the class teacher. Therefore, such activities seek to increase attention and engagement of students, and as a result, increase their learning.

Absorb-type activities mainly refer to information and knowledge and include information and attempt of learners to extract the concept from information. The learner may be physically passive but mentally active because he/she actively understands the processes, makes a hypothesis, and judges the information. In this type of activity, the learner attracts some of the information provided by the content. Absorb-type activities will be important and effective when the learner requires little information and wants to update and expand his knowledge. These types of activities can be used to stimulate and motivate the learners before learning and stabilize the learned content. These activities consist of 3 main parts: presentation, reading, and digital storytelling (4).

Presentations prepare clear and organized needed information with a logical sequence. They look like a conference in the classroom or are explained by an expert. Presentations are used to explain and demonstrate the initial information and stages of activity, model human behavior, and control the process of learning experiences. In a recorded presentation, the learner can control the speed of presentation, while in the live presentation, the learner can ask a question despite the fact that the provider dominates the situation. A variety of common and effective presentations in class are also common and effective in online and virtual courses.

Unlike traditional designs in which presentation is only done using slides, in the design of e-content, other types of presentations are used which are as follow: (1) physical presentation, which demonstrates a person performing a series of physical steps such as repairing corrupted tap or hitting the tennis ball; (2) software representation, which displays how to use a software by an expert; (3) informational films, which similar to documentary films, are used to teach, enhance information, and encourage people; (4) theater which places people in contrived situations such as showing a successful job inter- view; and (5) dialogues such as interviews, debates, and panel array are used to reveal important information and comments (4). Different studies have reported the followings: cases affecting the design of e-content including giving the controlling power to the user, allowing to print texts, providing more examples, combining presentation with exercise, adding introduction to user familiarity with the software, and how to move the slides using sublinks for further enrichment, linking the slides to references, using multimedia, and the ability to provide user feedback $(4,8$, 9). Figure 1 displays an example of a pilot project to enrich a presentation file.

The second absorb-type activity is to read and use ebooks. Reading is the main core of learning (10). E-learning can effectively use reading assignments. Through directing towards an individual or entire documents of the library, a learner can use papers or properly researched, organized, and written electronic documents and obtain valuable information and good ideas by studying them. In fact, written documents offer information organized in precise and predictable parts. Despite the challenges, in the study on reading in virtual space, Nielsen and Pernice reported that $79 \%$ of users scanned texts rather than reading them by viewing headings and summarizing and that those web users who read the whole text absorbed only $75 \%$ of what they read. Reading on a screen is $25 \%$ slower than reading a printed page, causing more eyestrain and pressure. On the other hand, internet users are active, not passive. If a glimpse does not demonstrate the information which they want, they will not spend the time to search for the information (11). However, Liang showed that those texts whose learner reads fast, studies, reads accurately, thinks, compares, rereads, notes, makes references, and gives feedback, can provide a more active learning experience than even learning games (12).

Among the features of suitable e-book, the following factors can be mentioned: the ability to offer multimedia: underlining important points; annotation; notes; marking in the book; highlighting the content; capability of magnification; ability to turn a page rather than scrolling without page; appropriate appearance; capability of multimedia (audio and video playback and educational films and animation); capability of double-media (connected to the master via the Internet); being interactive; and evaluating learners (13). In addition, the multimedia factor is important in increasing user interest in the use of ebooks. Online texts are rarely more than 1000 words. A good text has between 600 and 700 words (14). Therefore, a text should be written in a short and rich manner. Dynamic verbs such as listen to and look at the text should be used rather than using static verbs such as hear or see (15). To motivate reading, these activities can also be combined 


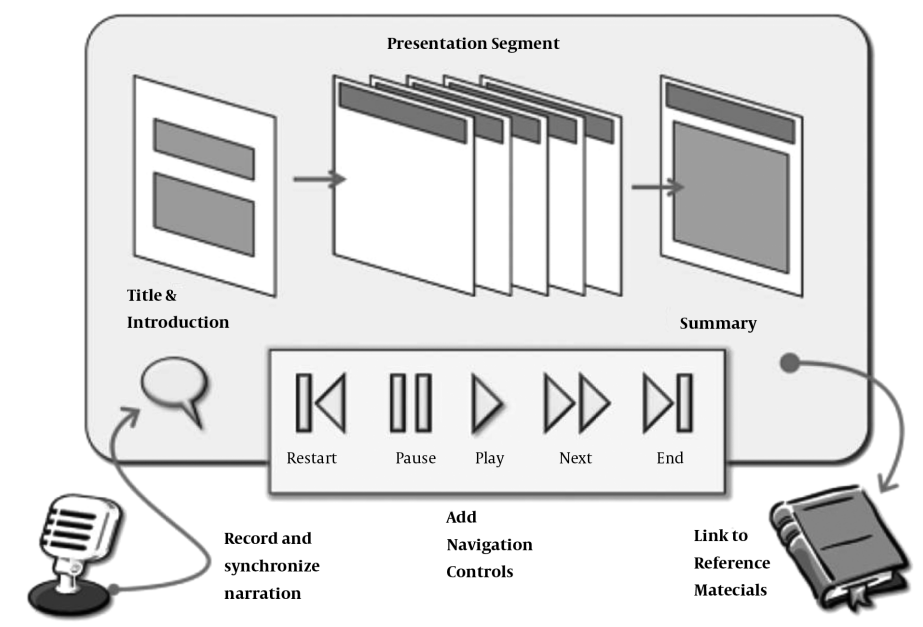

Figure 1. An Example of Enriching a Presentation File (4)

with other activities such as games or simulations. Table 1 demonstrates an example of these combinations.

One of the most important absorb-type activities is digital storytelling, which is an emerging field of higher education. The courses based on this method have been presented in the fields of communication and creative writing programs at a number of universities including University of California-Berkeley, University of Minnesota, and Empire State College (16). Moreover, the capacity of digital storytelling is beyond the field of communications and media studies and has been used in other fields including history, management, and trade (17), knowledge management (18), community planning (19), medicine, and health (20). Storytelling activities are associated with individual experiences and make information real and personal (21).

Several researchers have investigated various aspects of absorb-type activities. Suwardy et al. (22) used digital storytelling to engage students in learning. The results showed that using digital stories could be a suitable teaching method to help conceptualize in the field of business and have a positive impact on helping decision-making in students. Shelton et al. (23) performed digital storytelling in a consolidated period at a University. The results revealed that digital storytelling could interactively protect engagement and scaffold learning and increase learning, while it did not increase accountability. Stirling and Birt (24) conducted a study to evaluate the use of e-books enriched with multimedia and traditional methods in teaching cardiology anatomy. The preliminary results showed no significant difference in students' scores at the end of the course for using e-books. However, through the initial interaction with multimedia content and its contin- uation, the interaction of students' efficiency in the final test was increased. In fact, the positive role of e-books enriched with multimedia was confirmed compared to conventional methods in this study. By reviewing the presentations made in the area of e-learning at Latvia University of Agriculture, Paulins et al. (9) concluded that the presentations used the principles of design and multimedia could transfer e-materials to learners, with the lowest cognition compared to the face-to-face classes. However, they reported that presentations, not the used principles, had more cognitive load on learners than face- to- face classes.

Despite the studies on the effect of 3 types of activities including storytelling, presentation, and reading, few studies have examined the combination of these 3 activities (25). On the other hand, the effect of content and instructor on the success of e-learning has been reported more than student and virtual system (26). Thus, content can be considered as one of the effective factors in the field of e-learning. Moreover, most studies have reported the effect of any kinds of absorb-type activities compared to faceto- face education, while due to the increase in demand for e-learning courses and the need for higher quality in e-content design, evaluating and comparing the types of e-content design is of importance. Researchers found no study on comparing the content designed by absorb-type activities approach with other kinds of designs until the end of the investigation and writing of this study. Therefore, the main question is whether e-content designed by absorb-type activities approach can have a greater impact on students' learning and retention compared to common e-content. 
Table 1. Combining Reading with a Variety of Other Activities

\begin{tabular}{ll}
\hline Activities & How to Motivate to Read \\
\hline Game & Reviewing tests of facts, principles, and concepts from the read text \\
Simulation of software & The need to search for details on manual or online help \\
Images table game & Searching text for revealing the content interested in learner \\
\hline
\end{tabular}

\section{Methods}

This was a quasi-experimental study, with pre- and posttest and a control group. The study population included all third-grade students of a high school in the city of Tehran who were enrolled in the academic year of 2015 - 2016. A high school in Tehran was selected using convenience sampling method, and the students were randomly assigned into 2 experimental and control groups. Factors such as the type, method, and complexity of design, time, and location constraints, and previous studies are important when considering sample size and the minimal number in each group in causal-comparative and experimental studies is 15 (27). Because this study was experimental, the sample size considered for each of the experimental and control groups was 26 , and the total size of the sample was 52 individuals. Then, learning pretest was taken from them. To teach and prepare the content, magnetics theme of physics was selected, and e-content with absorbtype activities approach was designed and performed for the experimental group. In each session, the teacher first explained the contents using presentation in accordance with the lesson plan. The main points of how to design and do various activities were done at this stage. Subslides, physical, and laboratory presentations were used to implement magnetic forces, showing the same process in the virtual laboratory software. Then, a part of the documentary was shown to the students. Due to the limitation of the internet speed, the films were loaded on Aparat video sharing site, and its link was given to students. To receive feedback and solve the problems, students and teachers began to discuss the issue. In the second part of the class, the teacher recounted the concept in the form of a story position previously designed for students; and in the next sessions, the students tried to produce the story. Stories were on authentic or imagined situations in which people needed to solve their problems using magnetic forces. Two stories were designed by the teacher and 2 by the students. In each session, 2 resources including the main resources (i.e., textbooks and electronic monographs, supplement resources previously prepared as a book, e-articles, and links to the related web sites) were introduced.

In the control group, a common educational content was selected from e-contents on Roshd website (28) The content was designed according to the textbook in a way that its text was displayed and some of its images were displayed in an animation. Students were asked to read each page, turn to the next page, and at the end of each section, a multiple-choice test was given to them.

After completing 6 sessions, the first posttest (learning) was taken from both groups and 3 weeks later, the second posttest (retention) was administered on both groups. The data which were collected using SPSS version 16 underwent analysis.

In this study, 2 instruments of learning and retention tests made up of the magnetic issue. Pre- and posttest of learning and retention were designed with 20 objective multiple-choice questions. A positive score was allocated to each correct answer and a negative score to every 3 wrong answers to reduce the chance of guessing the answers. The final score was calculated using the lowest and highest scores, and the cut points were determined as 0 , 20 , and 10 , respectively. To ensure reliability, the test was given to 4 experts in the field. The specialty of 2 experts was electronics and physics. The face and content validity was confirmed as well. To measure the reliability of the tests, the learning test was performed for fourth-grade students passing this course, and the reliability of learning pre-and posttest with Cronbach's alpha coefficient was obtained as 0.82 and 0.89 , respectively. The reliability of retention test was also obtained as 0.76 in the fourth-grade students. After data collection, descriptive and inferential statistical methods were used for data analysis. Mean and standard deviation were used for descriptive statistics, and analysis of covariance was used to examine the hypotheses of the study using inferential statistics. Inclusion criterion was studying at the third grade of high school in the third Education district of Tehran, and exclusion criterion was violation of the inclusion criteria.

Given the ethical considerations observed in this study, all participants in the experimental and control groups were included in the study with full knowledge and consent. Because the students were younger than 18 , their parents were informed of the activities and implementation of the study and provided their consent. The demographic information was confidential, and a specific code was des- 
ignated for each student for the future uses of the data.

\section{Results}

The participants in the study were all male third grade high school students with an average age of $16.76 \pm 0.23$. The results of this study were first provided by comparing the scores at pre-and posttest; then, the hypotheses related to the learning and retention were evaluated in 2 parts.

The scores of the pretest, first posttest (learning), and second posttest (retention) for each group are displayed in Table 2.

Based on the results demonstrated in Table 2, in the experimental group, the mean scores of pretest, first posttest, and second posttest were $1.87 \pm 6.07$ with minimum 1 and maximum 10, $1.15 \pm 17.5$ with minimum 13 and maximum 20, and $2.41 \pm 1484$ with minimum 7 and maximum 19, respectively. In the control group, the mean scores of pretest, first posttest, and second posttest were $1.65 \pm 5.61$ with minimum 2 and maximum $9,1.89 \pm 14.61$ with minimum 12 and maximum 18, and $2.71 \pm 12.92$ with minimum of 4 and maximum 17.

In the response to the first hypothesis of the study, which was e-content designed by absorb-type activities approach, this method had more effect on student learning compared with the conventional e-contents. Considering the plan of the present study, which was of pre- and posttest type, the analysis of covariance was used to analyze data and control the effect of the pretest. The assumptions in the analysis of covariance (homogeneity of variances, normality, and equality of slope of regression lines) were assessed and confirmed. The results of analysis of covariance in relation to the first hypothesis have been reported in Table 3.

As demonstrated in Table 3, a significant difference was obtained among posttest mean scores after removing the effect of pretest, therefore, according to the obtained amount of $\mathrm{F}$ (33.62), it can be stated that e-content designed by absorb-type activities approach has significantly more effect on students' learning compared to conventional econtent.

Table 4 displays the response to the second hypothesis of the study, which is e-content designed by absorb-type activities approach, demonstrating more effect on students' retention compared with the conventional e-contents.

As presented in Table 4, a significant difference was observed among mean retention scores after removing the effect of pretest. Thus, according to the obtained amount of $\mathrm{F}$ (7.74), with $95 \%$ confidence, it can be stated that econtent designed by absorb-type activities approach has significantly more effect on students' retention compared with conventional e-content.

\section{Discussion and Conclusion}

The present study aimed at investigating the effect of standardizing e-learning content based on absorb-type activities approach on learning and retention of students. Absorb-type activities include presentations, reading, and storytelling. These activities are used when students' experience is limited to the subject and teacher's explanation is required. To investigate the study hypotheses, learning and retention of students trained by e-content, designed based on absorb-type activities approach, were evaluated in comparison to those of students who were educated by conventional e-content. The obtained results revealed a significant difference between learning and retention of students educated by absorb-type activities approach in the experimental group and those educated by conventional e-content in the control group. The results of the present study are consistent with those of the study by Sandars et al. in which they showed that digital storytelling could increase the involvement of first year medical students with content, and consequently having a positive effect on their learning (29). Suwardy et al. and Shelton et al. also reported the positive impact of storytelling (22, 24). The results of the present study were consistent with those of the study by Paulins et al. who reported the positive effect of enriched presentations (9). Our results are also consistent with those of the study by Amutha who reported the positive impact on e-learning content on first year university students' learning in the subject of science (30). However, our results are inconsistent with those of the study by McFall who observed no significant difference in the learning of students who used e- and printed books (31). Also, the results of the study by Gregory indicated that the students prefer to use printed books rather than ebooks (32). However, Nasri et al. reported that the learning and interest of those students who used e-books were more than those who used printed books; and by examining the conducted studies, they found the reasons for the lack of effect or negative affect cases, which were as follow: the habit of using printed books, the lack of skills in using related software and hardware, not having the required standards in e-books, and only scanning printed books (13).

The analysis of the results of the first hypothesis showed that e-content designed based on absorb-type activities approach was more effective on students' learning compared to the conventional e-content. The most important factor of this effectiveness was to involve students with e-content. In the learning content designed with these activities, students read, listen, and watch. In these activities, students think, select, combine, judge, and process information. In fact, in such activities the learners go out of passivity and become active in the learning pro- 
Table 2. Descriptive Indexes of the First Posttest (learning) and Second Posttest (Retention) for Each Group

\begin{tabular}{|c|c|c|c|c|}
\hline Statistical Description of Groups & Group & Mean & S.D. & No. \\
\hline \multirow{2}{*}{ Pretest } & Experimental & 6.07 & 1.87 & 26 \\
\hline & Control & 5.61 & 1.65 & 26 \\
\hline \multirow{2}{*}{ Posttest (learning) } & Experimental & 17.15 & 1.15 & 26 \\
\hline & Control & 14.61 & 1.89 & 26 \\
\hline \multirow{2}{*}{ Posttest (retention) } & Experimental & 14.84 & 2.41 & 26 \\
\hline & Control & 12.92 & 1.71 & 26 \\
\hline
\end{tabular}

Table 3. Analysis of Covariance

\begin{tabular}{lcccc}
\hline Variables & Sum of Squares & Degree of Freedom & Mean Square & F \\
\hline Pretest & 17.90 & 1 & 17.90 & 8.30 \\
Group & 17.48 & 1 & 17.48 & 33.62 \\
Error & 105.63 & 49 & 2.15 & 0.006 \\
Total & 13328 & 51 & & 0.001 \\
\hline
\end{tabular}

Table 4. Analysis of Covariance

\begin{tabular}{lcccc}
\hline Variables & Sum of Squares & Degree of Freedom & Mean Square & F \\
\hline Pretest & 157.07 & 1 & 157.07 & 44.71 \\
Group & 27.22 & 1 & 27.22 & 7.74 \\
Error & 172.15 & 49 & 3.51 & \\
Total & 10402 & 51 & & \\
\hline
\end{tabular}

cess through techniques such as providing feedback, sharing stories, and engaging in content production. The possibility to control teaching processes by learners and go back for teaching again adjusted the learning rate according to the needs of each learner.

The analysis of the second hypothesis showed that econtent designed based on absorb-type activities approach affected students' retention more compared to conventional e-content. Absorb-type activities recall past learning and transfer deeper learning through enhancing e-content by more examples and exercises. In addition, providing additional resources for each subject matter leads to creating an atmosphere of personalized learning content to help learners in their favorite subjects beyond the curriculum and leads to deeper learning.

The innovation of this study can add to the results of previous studies including the investigation of standardization of e-content and its effect on conventional content in e-learning rather than face- to- face learning. The study was conducted in such a way that both experimental and control groups were trained in the e-learning environment with a subject matter, but with content designed in standard and conventional methods. Standards are of high importance in maintaining quality, gaining the trust of students and service providers, and integrating various activities and actions; they are a critical component of any industry and technology. By providing a set of common frameworks and general guidelines, standards include guidelines for achieving the objectives such as improving the quality, interoperability, integration, and reuse of the educational contents. Although standards create limitations for manufacturers and developers, the necessary considerations for updating them cause rapid growth and increase the speed (33).

The small statistical sample and caution in generalizing the results to students in other educational levels and cities were the limitations of this study. Due to the lack of preparation of most schools, with respect to software and hardware, to implement e-learning courses, the convenience sampling method was selected, so it would be possible to affect the extension of the results. This study was conducted exclusively on a lesson topic in the field of 
physics. Therefore, it is recommended to evaluate the effect of absorb-type activities on different subjects such as humanities or natural sciences in future studies.

This study investigated one of the new approaches to design e-content in e-learning. This approach is suitable to new and text-based subjects on which users have fewer experience and need to be taught by a teacher. This approach is indeed one of the 3 approaches to design e-content. Therefore, it is recommended that future studies examine the 2 other approaches, i.e., do- and connect-type activities. E-content would have the best result and effect when the three design approaches based on absorb-, do-, and connect- type activities have been used.

\section{Acknowledgments}

The authors would like to thank Roozbeh Educational Complex for all the support and the students for participating in this study.

\section{References}

1. Fallon C, Brown S. E-learning standards: a guide to purchasing, developing, and deploying standards-conformant e-learning. CRC Press 2016.

2. Ghasemi Z, editor. Effective factors in e Learning. Paper presented at the 4 th Conference on eLearning in medical science [In Persian].2010; Iran, Tabriz.

3. Shokoohi M, Emami S, editors. Standardization of e Content and its effects on learning motivation [In Persian]. Paper presented at the 2nd international conference on electronic city. 2009; Iran, Tehran.

4. Horton W. E-learning by design. John Wiley and Sons; 2011.

5. Forsyth H, Pizzica J, Laxton R, Mahony MJ. Distance education in an era of eLearning: challenges and opportunities for a campusfocused institution. High Educ Res Dev. 2010;29(1):15-28. doi: 10.1080/07294360903421350.

6. Islam N, Beer M, Slack F. E-learning challenges faced by academics in higher education: A literature review. J Educ Train Stud. 2015;3(5) doi: 10.11114/jets.v3i5.947.

7. Zangeneh $\mathrm{H}$, Pourjamshidi M, Velayati E, Abolghasemi E. A practical framework for management of cognitive load in design and development of electronic content [In Persian]. Quart J Technol Instr Learn. 2015;1(4):105-24

8. Clark RC, Mayer RE. E-learning and the science of instruction: Proven guidelines for consumers and designers of multimedia learning. ; 2016.

9. Paulins N, Balina S, Arhipova I, editors. E-learning material presentation and visualization types and schemes. In Proceedings of the 16th International Conference on Enterprise Information Systems. 2014; pp. 138-43.

10. Clarke A. E-learning skills. Palgrave Macmillan; 2008.

11. Nielsen J, Pernice K. Eyetracking web usability. New Riders; 2010.

12. Liang TH. The effects of keyword cues and 3R strategy on children's e-book reading. J Comput Assisted Learn. 2015;31(2):176-87. doi: 10.1111/jcal.12072.
13. Nasri SH, Zaraii Zavaraki E, Armand M, Rezaie E. Design and development of electronic textbook and its effects on learning and attitudes of students. J Res Dev Academic Textbooks. 2012;16(27):82-98.

14. Fahimifar S. E-book collections in academic libraries of metropolitan Tehran. J Infom Proc Manage. 2008;23(3):53-75.

15. Kamil ML, Mosenthal PB, Pearson P, Barr RE. Handbook of reading research. III. Lawrence Erlbaum Associates Publishers; 2000.

16. McLellan H. Digital storytelling in higher education. J Comput High Educ. 2007;19(1):65-79. doi: 10.1007/bf03033420.

17. Stepanek M. The power of digital storytelling. Business week 2010. Available from: http://www.businessweek.com/2000/00_20/ b3681104.htm.

18. Sawyer RC. Knowledge Management (KM), digital media, and storytelling. Fielding Graduate University; 2015.

19. LeBron AM, Schulz AJ, Bernal C, Gamboa C, Wright C, Sand S, et al. Storytelling in community intervention research: lessons learned from the walk your heart to health intervention. Prog Community Health Partnersh. 2014;8(4):477-85. doi: 10.1353/cpr.2014.0066. [PubMed: 25727980].

20. Cueva M, Kuhnley R, Revels L, Schoenberg NE, Dignan M. Digital storytelling: a tool for health promotion and cancer awareness in rural Alaskan communities. Int J Circumpolar Health. 2015;74(1):28781. doi: 10.3402/ijch.v74.28781. [PubMed: 28417783].

21. Duman B, Göcen G. The effect of the digital storytelling method on pre-service teachers' creative writing skills. Anthropol. 2015;20(12):215-22.

22. Suwardy T, Pan G, Seow PS. Using digital storytelling to engage student learning. Account Educ. 2013;22(2):109-24. doi: 10.1080/09639284.2012.748505.

23. Shelton CC, Warren AE, Archambault LM. Exploring the use of interactive digital storytelling video: Promoting student engagement and learning in a university hybrid course. TechTrends. 2016;60(5):465-74. doi: 10.1007/s11528-016-0082-z.

24. Stirling A, Birt J. An enriched multimedia eBook application to facilitate learning of anatomy. Anat Sci Educ. 2014;7(1):19-27. doi: 10.1002/ase.1373. [PubMed: 23650104].

25. Kanani H, Enayati T, Zameni F. Assessing the effect of e-books on mazandaran high school students' tendency to study during 20112012 [In Persian]. Media. 2013;3(4):6-7.

26. Golband F, Mojtahedzadeh R, Hosseini AF, Mirhosseini F, Bigdeli SH. Effective e-learning view point of tehran university of medical sciences virtual faculty post-graduate students [In Persian]. Educ Strategies Med Sci. 2014;7(2):93-7.

27. Biyabangard E. Research methods in psychology and education. Doran. 2010.

28. Available from: http://elearning.roshd.ir/samin/search.asp?keyw= all\&ftype $=0 \&$ fyear $=3 \&$ fkind $=1 \&$ fchapter $=16$.

29. Sandars J, Murray C, Pellow A. Twelve tips for using digital storytelling to promote reflective learning by medical students. Med Teach. 2008;30(8):774-7. doi: 10.1080/01421590801987370. [PubMed: 18946821].

30. Amutha S. Impact of e-content integration in science on the learning of students at tertiary level. Int J Inform Educ Technol. 2016;6(8):643-6. doi: 10.7763/ijiet.2016.v6.766.

31. McFall R. Electronic textbooks that transform how textbooks are used. Electron Library. 2005;23(1):72-81. doi: 10.1108/02640470510582754.

32. Gregory CL. But I Want a Real Book". RefUser Serv Q. 2008;47(3):266-73. doi: $10.5860 /$ rusq.47n3.266.

33. Mehrban MH, Mosalanejad M. Standard instructional content in information technology and elearning. Paper presented at International Conference on Education and Engineering. Tehran. . 